\title{
The ESPERIA satellite project for detecting seismo-associated effects in the topside ionosphere. First instrumental tests in space
}

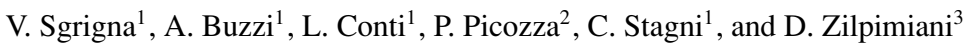 \\ ${ }^{1}$ Department of Physics and INFN Branch, Roma Tre University 84, Via della Vasca Navale, 00146 Rome, Italy \\ ${ }^{2}$ Department of Physics and INFN Branch, Tor Vergata University, Rome, Italy \\ ${ }^{3}$ Institute of Geophysics, Georgian Academy of Sciences (GAS) and National Space Agency, Tbilisi, Republic of Georgia
}

(Received November 13, 2006; Revised September 13, 2007; Accepted October 24, 2007; Online published May 16, 2008)

\begin{abstract}
In recent times, ionospheric and magnetospheric perturbations constituted by radiation belt particle precipitations, variations of temperature and density of ionic and electronic components of ionospheric plasma as well as electric and magnetic field fluctuations have been detected on board of the LEO satellites and associated with earthquake preparation and occurrence. Several mechanisms have been suggested as justifying the seismoelectromagnetic phenomena observed in the upper lithosphere and in the topside ionosphere before, during and after an earthquake. Their propagation in these media has also been investigated, but physical knowledge of such processes is below standard. Consequently, coordinated space and ground-based observations based on data gathered simultaneously in space and at the Earth's surface are needed to investigate seismo-associated phenomena. To this end, the ESPERIA space mission project has been designed for the Italian Space Agency (ASI). To date, a few instruments of its payload have been built and tested in space. This paper reports on the justification, science background, and characteristics of the ESPERIA mission project as well as the description and testing of ESPERIA Instruments (ARINA and LAZIO-EGLE) in space.
\end{abstract}

Key words: Seismicity, earthquake precursors, seismo-electromagnetic emissions, satellite, ionosphere.

\section{Introduction}

It is well known that earthquakes are a manifestation of significant ground rock deformation events-i.e. episodic deformations of the upper and, more or less, brittle layers of the Earth's lithosphere. These can be classified as fast seismic ruptures, slow earthquakes and sub-seismic events. Since the energy released during large earthquakes affects human life, the development and application of appropriate and efficient techniques to defend society from these destructive effects are necessary. At the present time, only two suitable approaches are available: damage prevention and prediction methods.

Earthquake damage prevention implies the development of both methods for evaluating seismic risks in order to enable disaster assessment and techniques for use in estimating seismic risk, with the ultimate aim of reducing damage produced by earthquakes through reliable means. Therefore, the prevention of damage is achievable with existing state of knowledge. In fact, in the prevention approach, more effort is required to discover new unknown scientific aspects of the topic. A great importance lies in the optimization of methods necessary to determine the three main factors - vulnerability, value and hazard — which define seismic risk as well as in managing the results obtained by this approach.

In contrast, the problem of prediction on a determinis-

Copyright (c) The Society of Geomagnetism and Earth, Planetary and Space Sciences (SGEPSS); The Seismological Society of Japan; The Volcanological Society of Japan; The Geodetic Society of Japan; The Japanese Society for Planetary Sciences; TERRAPUB. tic basis, with the aim of providing the possibility to predict time of origin, hypocentral (or epicentral) location and magnitude of an impending earthquake, is an open scientific problem. The reason for this is that such predictions are based on the detection of the so-called earthquake precursors or pre-earthquake phenomena, and the physical interpretation of these is a very complicated matter.

At this point, a few main concepts on precursor detectability must be considered. First, it must be clear that reducing "physics of the earthquake" only to the creation of fault rupture and consequent seismic wave propagation is to over-simplify the problem.

In fact, it has been repeatedly observed that part of the accumulated (pre-seismic) elastic energy is also converted to other kind of energies (electromagnetic, acoustic, heat, among others) and that these conversion mechanisms are probably similar to that of seismic energy.

Moreover, observations during inter-seismic and preseismic periods indicate that large earthquakes are often preceded by signals of different natures (the so-called earthquake precursors), of which the mechanical (tilt and strain), gaseous (helium and radon) and electromagnetic ones have been demonstrated to be the most significant manifestations (see this paper and also Sgrigna et al., 2006). This explains why researchers are often induced to direct their efforts towards the monitoring and interpretation of these preearthquake phenomena. However, the study of the physical conditions that give rise to an earthquake and of the processes that precede a seismic rupture are at a very preliminary stage and, consequently, the techniques of prediction 
available at the moment are below standard.

In trying to by-pass these difficulties, many investigators have likely been attracted by a statistical prediction approach based on the so-called earthquake forecasting method, that is the probability of occurrence of an event in a given geographical location, within assigned values of magnitude and time ranges. However, even though the forecasting methods, such as those of the M8 and CN algorithms (e.g. Keilis Borok, 1996; Keilis Borok and Soloviev, 2003; Peresan et al., 2005) or of the acceleration deformation approach (e.g. Tzanis and Vallianatos, 2003) have reached a very good level of maturity and can display a good level of importance and practical use, they overlap with the seismic hazard concept, one of the three factors used to estimate seismic risk. This could result in a possible ambiguity in the application of earthquake prediction and earthquake damage prevention approaches, which could give rise to a kind of "methodological noise" that would be capable of introducing systematic errors in the use of the two methods.

We therefore believe that it should be better to pursue the deterministic prediction approach based on the physics of earthquake precursors even if a reliable deterministic method of earthquake prediction will presumably be available only in the more distant future.

This latter conclusion is also confirmed by the underestimated expectation of earthquake prediction in a relatively short period of time based on the basis of seismic precursor studies carried out in the last decades. As mentioned above, the physics of earthquakes has been demonstrated to be a very complicated matter.

Nevertheless, research with this aim continues with a critical view, new ideas and thorough investigations. The results of such studies seem to be promising.

Progress in this area could be due not only to increased amounts and accuracy of ground field measurements, careful attention to errors in data, and improved understanding of earthquake source mechanics but also-and possibly most importantly-to a new approach based on observations from space.

Electromagnetic (EM) emissions (EME) radiated from the Earth's surface and produced as a consequence of earthquake preparation and occurrence or by human activities have been shown to cause perturbations in the topside ionosphere and to be detectable by Low-Earth-Orbit (LEO) satellites (Sgrigna et al., 2002a, 2005a, 2006; Pulinets, 2006).

Within this framework, natural disasters, such as earthquakes, and the impact of anthropogenic EME in the nearEarth space can also be considered as coupling elements of the lithosphere-atmosphere-ionosphere-magnetosphere interactions.

Consequently, space observations are being performed, or are going to be carried out, in the ionospheremagnetosphere transition region, and a few satellite missions (Demeter, QuakeSat, Sich-1M, Compass-1/2, Egle, Esperia, Arina, among others) have already been carried out and/or are proposed from 2001 until the present (Long et al., 2002; Parrot, 2002; Sgrigna et al., 2001, 2006; Picozza, 2003).

The basic premise is that observations of different ground and space seismic precursors as well as laboratory experiments on rocks and the development of theoretical models, all of which aimed at placing the phenomenon "earthquake" within the framework of a unified theory, would be able to explain the causes of its genesis, and the dynamics, rheology and micro-physics of its preparation, occurrence, post-seismic relaxation and inter-seismic phases. The physical system to be considered includes solid Earth and near-Earth space with related couplings and perturbations. Also, it is hoped that a better scientific coordination on an international basis between diverse teams of researchers would smooth out and integrate different methodological approaches relatively to each other for a better use of the different competences, instruments and databases.

We believe that the best approach is to plan and design coordinated and simultaneous ground-based measurements, carried out by network of instruments in test sites of diverse seismic areas, and multi-parametric space observations onboard satellites, together with the development of appropriate methods of data analysis and theoretical modeling.

To this end, we have installed the TELLUS tilt network in the seismic area of the Central Apennines of Italy. This network will, in the near future, also include magnetometers and specific devices to detect electric field. Results obtained by the TELLUS network have been reported (Sgrigna and Malvezzi, 2003). Within the framework of a guest investigation programme we are now studying data collected in the topside ionosphere by the DEMETER micro-satellite. At the same time, we also have made first attempts to develop a theoretical model of the genesis and propagation of pre-earthquake electromagnetic emissions in the lithosphere and near-Earth space (atmosphere, ionosphere, magnetosphere). Theoretical modeling and DEMETER data analysis are in the beginning stage, but a few over preliminary results have been reported in international congresses (Sgrigna et al., 2002a, b; Conti et al., 2005).

In this paper we will describe the ESPERIA mission project (Sgrigna, 2001) together with the description and testing of the first ESPERIA instruments (ARINA and LAZIO-EGLE) in space (Picozza, 2003; Sgrigna et al., 2005b). We will also present the main results about ground and space pre-earthquake phenomena and their reliability as a justification for this project and provide information on the scientific background.

\section{More Reliable Earthquake Precursors}

A method that allows medium-term (approx. weeksyears) and short-term (approx. hours-weeks) earthquake predictions has not yet been developed, but there are systematic observations of intermediate-term and short-term earthquake precursors, a few of which have been shown to be suitable for future applications.

The main results on this topic are presented here. The material is divided into ground and space observations and into intermediate-term and short-term precursors, respectively.

This scientific background will give an idea (though not exhaustive) of the state-of-the-art in the topic. 


\subsection{Creep-related ground tilt intermediate-term pre-} cursors

A number of interesting results concerning anomalous surface tilt variations observed during earthquake preparation have been reported over the years. They include the observation and modeling of creep-related tilt perturbations (McHugh and Johnston, 1979; Bella et al., 1995; Sgrigna and Malvezzi, 2003), precursory tilts detected before local and teleseismic earthquakes (Bilham, 1981; Bilham et al., 1985), coseismic and postseismic tilts (Thatcher and Fujita, 1984). These anomalies are easily detectable by tiltmeters (Mortensen and Johnston, 1975; Bilham and Beavan, 1979; Nur et al., 1986; Bella et al., 1995; Sgrigna and Malvezzi, 2003) and considered by many authors (Ida, 1974; Pevnev, 1988, 1989; Bilham, 1981; Bilham et al., 1985; Bella et al., 1986a, 1993, 1995; Sgrigna et al., 2002b) to be intermediate-term earthquake precursors.

Continuous hourly ground tilt data collected by the TELLUS tiltmeter network from 1981 to the present in the seismic region of the Central Apennines of Italy has systematically provided evidence of intermediate term-earthquake tilt precursors (Sgrigna and Malvezzi, 2003). The main features of tilt signals observed in this seismic zone are summarized as follows:

1. Raw tilt data filtered by meteorological and secular tectonic effects revealed intermediate-term preseismic tilts with a shape, amplitude and time duration similar to those already obtained in the same area (Bella et al., 1986a, 1993, 1995; Sgrigna and Malvezzi, 2003).

2. Tilts are shifted in time relative to each other, indicating a possible propagation of the pre-seismic strain field from the preparation focal area to the tilt sites, through the rigid blocks of the region (Salvini, 1993; Bella et al., 1998) separated by inclined transition zones, filled by fault visco-elastic material (Ida, 1974; Bilham, 1981; Bella et al., 1986b; Sgrigna and Malvezzi, 2003).

3. Experimental values for the velocity of propagation are in agreement with previous results.

4. The intermediate-term pre-seismic tilts have been interpreted as visco-elastic creep strains in the fault material, due to the propagation of stress-strain fields from the dilatant focal area to the observation sites.

5. One dimensional and two-dimensional numerical models have been proposed to justify qualitatively the main features (tilt anomaly shape and onset time delay and decay of anomaly amplitude with distance from the earthquake preparation zone) of the pre-seismic ground tilt behavior (Bella et al., 1990, 1998; Sgrigna et al., 2002b). Horizontal movements of rigid crustal blocks were also considered by Gabrielov et al. (1990).

\subsection{Ground and space short-term seismic-associated EME signals}

The first systematic list of electric phenomena associated to earthquakes was made by Galli (1910) who reported that 148 luminous phenomena occurred in Italy: 52 before and 37 during and after the associated earthquake. The most frequent phenomena reported are flashes occurring during the earthquake.

The luminescent clouds and diffuse lights are reported before during and after the earthquake. More generally, studies of seismo-electromagnetic emissions (SEME) have been developed for a few decades both at the Earth's surface and in the near-Earth space (atmosphere, ionosphere, and magnetosphere).

In recent years, interest has been increasing in the SEME signals consisting of a broad band (from approximately DC to a few tens of $\mathrm{MHz}$ ) EM fields generated and transmitted by seismic sources into the near Earth's space before, during and after an earthquake. SEME characteristics and detectability have a very interesting and promising nature as a short-term earthquake predictor. To provide details on such an indication we give an outline here on the main observations and models on the subject.

Ground-based measurements revealed slow electrotelluric and magnetic field variations (Johnston and Mueller, 1987; Varotsos et al., 1993; Nomikos et al., 1997) as well as pre-seismic ground potentials. The latter are generated as streaming potentials when saline water moving through porous rocks entrains ionic charges (Draganov et al., 1991; Bernabé, 1998) or when stress is applied to rocks containing (or not) piezoelectric minerals such as quartz (Bishop, 1981; Varotsos et al., 1997; Freund, 2002; Stavrakas et al., 2003). The transmission of substantial stress over large distances has been debated (Geller, 1996; Sgrigna et al., 2002a; Sgrigna and Malvezzi, 2003).

It has been shown (Areshidze et al., 1992; Bella et al., 1995; Guo et al., 1994; Molchanov and Hayakawa, 1998) that rock micro-fracturing releases gas (radon, helium) and causes electrical conductivity changes as a function of micro-crack number and dimension and of the redistribution of pore fluids (the motion of saline pore fluids may cause the formation of inter-granular water film).

Freund (2003) has recently proposed that dry rocks can also become a source of highly mobile electronic charge carriers that increase the electric conductivity and potentially propagate through the rock as a charge cloud. Laboratory experiments carried out by Freund et al. (2006) pointed to a kind of "igneous rock battery" due to the activation of positive hole charge carriers by stress (dislocation movement leading to bond breaking of Si-OO-Si peroxy links. At low frequencies, this appears to be a reasonable description of how part of the accumulated pre-seismic elastic energy is converted to electromagnetic energy.

Ground low-frequency (ULF/ELF) EME-signals have also been documented in connection with relevant earthquakes (Kopytenko et al., 1993; Fraser-Smith et al., 1994; Ismaguilov et al., 2001; Ohta et al., 2001) and preliminary, though not exhaustive, explanations have been reported on the subject (Park et al., 1993; Merzer and Klemperer, 1997; Molchanov and Hayakawa, 1998; Surkov, 1999; Hayakawa et al., 2000).

One possible scenario is to consider these perturbations as being due to SEME-waves generated by preseismic sources and transmitted into the near-Earth space (see, for instance, Dobrovolsky et al., 1989; Guo et al., 1994; Fenoglio et al., 1995; Molchanov et al., 1995; Teisseyre, 1997; Grimalsky et al., 1999; Vallianatos and Tzanis, 
1999; Pulinets et al., 2000; Sorokin et al., 2001; Gershenzon and Bambakidis, 2001; Fujinawa et al., 2002; Hayakawa et al., 2002; Freund, 2003). During the propagation from the hypo-central source to the Earth's surface, the higher frequency content of the ULF-HF EME-waves is attenuated, and only ULF/ELF EME-waves are supposed to reach the Earth's surface and enter into the nearEarth space, where they cause perturbations (total electron content (TEC) changes, ionospheric motions, joule heating, etc.) in the atmosphere and ionosphere (Blanc, 1985; Molchanov et al., 1995; Zaslavski et al., 1998; Ohta et al., 2001). Only in the case of very shallow and strong earthquakes, when the size of the preparation focal zone is greater than the hypo-central depth could a higher frequency content of this EM radiation be transmitted from the Earth's surface to the near space.

More generally, results of local ground-based SEME observations have been obtained on a larger (ULF through to HF) frequency band (see, in addition to the abovementioned authors, Warwick et al., 1982; Oike and Ogawa, 1986; Johnston, 1997; Bella et al., 1998; Uyeda et al., 1999; Eftaxias et al., 2003; Vallianatos et al., 2004). Recently, Nardi and Caputo $(2005,2006)$ reported laboratory and field observations of electric signals. They showed that these signals are generally of the same type-particularly in the VLF band.

Another scenario for SEME disturbances is to consider them as a secondary effect produced by other mechanisms induced by seismic activity (Molchanov et al., 1993).

Fair weather currents have also been proposed to justify variations in the atmospheric conductivity profiles (Pulinets et al., 2000). Pre-seismic changes of the tropospheric conductivity profiles have also been associated with modifications of the spectral content of ELF-VLF radio noise during lightning discharges (Hayakawa et al., 2002).

Research on disturbances in radio-wave propagation produced by seismic activity has also been carried out (Hayakawa and Sato, 1994; Morgounov et al., 1994; Gufeld et al., 1994; Bella et al., 1998). Such analyses are based on the amplitude and phase variations of radio-signals propagating in the earth-ionosphere wave-guide and emitted by diverse transmitting stations.

Significant short-term earthquake precursors were obtained by investigating the propagation of Omega and Loran VLF radio-waves used for world-wide navigation (Hayakawa and Sato, 1994; Morgounov et al., 1994; Gufeld et al., 1994). Also, a short-term attenuation in the electric field strength of the LF radio-signal emitted by the Radio Monte Carlo (RMC) broadcasting station was observed at a receiver of Central Italy prior to local earthquakes (Bella et al., 1998).

These short-term pre-seismic variations of several days have been explained by the presence of abnormal ionisation in the lower ionosphere (Morgounov et al., 1994) and tropospheric radio defocusing mechanisms (Bella et al., 1998).

Fujiwara et al. (2004) observed that the appearance of atmospheric anomalies associated with the anomalous transmission of VHF EM-waves beyond line-of-sight was significantly enhanced within the 5-day period immediately preceding earthquakes of moderate magnitude (generally,
$M \geq 4.8$ ).

More recently, Liu et al. (2006) reported empirical evidence of the pre-seismic ionospheric anomalies by statistically investigating the relationship between variations of the plasma frequency at the ionospheric $\mathrm{F} 2$ peak $f_{0} \mathrm{~F} 2$ and 184 earthquakes with magnitude $M \geq 5.0$ during 1994-1999 in the Taiwan seismic area. The anomalies were defined as an abnormal decrease (greater than 25\%) in the above ionospheric F2 peak during the afternoon period that occurred in the 5-day period immediately preceding the earthquakes. The correlation between these two classes of events was shown to be energy related since it increases with earthquake magnitude and decreases with distance.

\subsection{Space short-term precursors}

The results of satellite measurements in the near-Earth space demonstrated the presence of short-term earthquake precursors constituted by electric and magnetic anomalies and EME signals; these were accompanied by perturbations of comparable duration in the temperature and density of the ionospheric plasma and anomalous bursts of highenergy particles precipitating from the inner Van Allen radiation belt.

Space observations of ionospheric perturbations over seismic regions have been reported and discussed on the occasion of several strong earthquakes (Gokhberg et al., 1979; Larkina et al., 1989; Parrot and Mogilevsky, 1989; Bilichenko et al., 1990; Serebriakova et al., 1992; Parrot et al., 1993; Chmyrev et al., 1997; Rodger et al., 1999; Lee et al., 2000; Pulinets et al., 2000; Hayakawa et al., 2002; Aleksandrin et al., 2003; Sgrigna et al., 2005a).

Satellite observations seem to confirm the aboveillustrated scenarios. Indeed, preseismic changes in electric and magnetic fields (Molchanov et al., 1993; Parrot, 1994; Rodger et al., 1999) and of ionospheric plasma temperature and density (Parrot and Mogilevsky, 1989; Parrot et al., 1993; Chmyrev et al., 1997) have been observed from a few minutes to several days prior to earthquakes of moderate or strong magnitude (generally greater than 4.0).

A relatively new result is that preseismic EM disturbances produced in a seismic area with one of the abovedescribed mechanisms are thought to reach the inner Van Allen radiation belt, where they may interact with trapped particles (Galperin et al., 1992). In confirmation of this hypothesis, in the last two decades, a very interesting and new phenomenon has been observed in the ionospheremagnetosphere transition region. This consists of anomalous particle fluxes detected by several space experiments and reconciled with the earthquakes occurrence (Galper et al., 1989; Voronov et al., 1990; Aleshina et al., 1992; Pustovetov and Malyshev, 1993). These events are characterized by an anomalous short-term and sharp increase of highenergy radiation particle precipitation. In the following text, they are referred to as "particle bursts" (PBs). Most PBs have been collected by satellites near the South Atlantic Anomaly (SAA) at altitudes generally between about 400 and $1200 \mathrm{~km}$ (Pustovetov and Malyshev, 1993; Ginzburg et al., 1994; Galper et al., 1995).

Larkina et al. (1989) and, more recently, Aleksandrin et al. (2003) and Sgrigna et al. (2002a, 2005a) also attempted to confirm the preseismic character of these PBs by using 
PBs-EQs statistical correlations under the hypothesis that preseismic ULF/ELF EME wave-trapped particle interaction may cause the precipitation of Van Allen belt electrons and protons.

With this purpose in mind, several authors (Aleshina et al., 1992; Galperin et al., 1992; Galper et al., 1995; Krechetov, 1996) proposed that in a certain portion of the ionosphere-magnetosphere transition zone such a lowfrequency content of SEME radiation (from DC to some hundred $\mathrm{Hz}$ ) can propagate as Alfven waves along the geomagnetic field lines. Near the radiation belt boundary, the waves may resonantly interact with trapped particles (electrons and protons from a few $\mathrm{MeV}$ to several tens of $\mathrm{MeV}$ ), thereby causing particle precipitation as a result of pitch angle diffusion. The lifetime of the longitudinal drift of PBs is determined by the particle loss rate during particle interaction with the residual atmosphere of the Earth. During this time, particles may drift longitudinally around the Earth along the L-shell corresponding to the EME ground source location (Aleshina et al., 1992; Galper et al., 1995). This is a crucial factor for a possible use of pre-seismic PBs as an earthquake predictor since the longitudinal drift makes the PB detection possible by particle detectors installed on board satellites. Another important factor is the opposite drift direction of positive and negative charged particles, which in principle could allow the location of EME waveparticle interaction zone (i.e., the PBs space source location) to be identified.

In addition, VLF EM-waves were observed from Intercosmos-24 satellite measurements (Molchanov et al., 1993). Data collected by this mission demonstrated that ULF emissions of 0.2 nT can penetrate through the ionosphere and interact with energetic protons of $0.5-5 \mathrm{MeV}$ near the magnetic equatorial plane. As a consequence of this cyclotron interaction, the proton distribution function can become unstable for the Cherenkov radiation of VLF waves in the frequency interval $0.1-20 \mathrm{kHz}$ (Krechetov, 1996).

Nevertheless, there is still an open debate on the mechanism to be invoked in order to justify the phenomenology under study and, in particular, whether the very lowamplitude ULF/ELF EM waves may reach the inner Van Allen radiation belt and cause the above-mentioned coupling phenomena. In fact, the electric and magnetic components of these EME-waves are estimated to be of only some fraction of $\mathrm{mV} / \mathrm{m}(\mathrm{Hz})^{1 / 2}$ and of some fraction of $\mathrm{nT} /(\mathrm{Hz})^{1 / 2}$ or less, respectively (Parrot et al., 1993).

\section{The ESPERIA Space Project}

ESPERIA is an equatorial magnetic, plasma and particle mission planned with a LEO small satellite. Its primary aim is to detect any tectonic- and pre-seismic-related signals (www.esperia-satellite.it). It has been proposed for monitoring perturbations in the topside ionosphere and for defining the near-Earth magnetic environment. The project aims at reconciling these phenomena with seismic-related signals from the Earth's surface. In particular, electromagnetic emissions related to strong earthquakes and possibly caused by stress changes in the crust are a main scientific objective of this mission project.
The identification of electromagnetic emissions of seismic origin, the impact of anthropogenic electromagnetic radiation in the near-Earth space, atmospheric electromagnetic emissions during thunderstorm activity and the effects of the sun and cosmic rays in the geomagnetic cavity were also taken into account during the ESPERIA Phase A Study, which was performed for the Italian Space Agency (ASI).

ESPERIA has the same important scientific objectives and a similar payload as the DEMETER mission. Also, the Principal Investigators of the two science teams are collaborating each other, within the activities of the DEMETER guest research programme.

ESPERIA includes a modular multi-instrument science payload constituted by a magnetic field analyzer (flux-gate and search-coil vector magnetometers), an electric field analyzer (a constellation of ten electric probes), a particle detector and an ionospheric plasma analyzer (Langmuir Probe and Retarding Potential Analyzer).

Most of these instruments are used extensively in nearEarth Space investigations, therefore ESPERIA, with some relatively small changes and/or augmentation of its Payload, can easily be adapted for studying most of the applications mentioned above. ESPERIA can also be seen as an equatorial coordinated and simultaneous complement to polar missions such as SWARM or the NASA "Living with a Star" Program.

A detailed technical description of the ESPERIA space mission concept can be found in the ASI Phase A Report (Sgrigna, 2001). We present only a synthesis of this space project here together with its scientific context.

\subsection{ESPERIA mission concept}

The ESPERIA instruments are planned to provide a costeffective survey of earthquake forecasting. Instruments and orbital parameters are structured to reach the final goals on the basis of general and specific requirements concerning scientific, technical and methodological aspects of the mission.

The fundamental aspects of the ESPERIA mission are summarized as follows:

\section{General requirements:}

- Coordinated space and ground measurements.

- Simultaneous and continuous measurements of the different parameters with an excellent capability for detecting particles over a broad energy rang, as well as for revealing plasma instabilities and electromagnetic fluctuations.

- Repeatability and maximum density of ground tracks over selected seismic regions with high-accuracy and short revisit time for a continuous ground monitoring of local and short-term earthquake precursor phenomena.

Specific requirements:

a. Optimization of orbital parameters

- Continuous monitoring (no necessity to apply "survey" and "burst" modes).

- Efficiency and low costs of the ground segment operability, including optimization in the use of mass memory by frequent down-link procedures. 
- High-sensitivity measurements in zones with relatively minimum time and space field changes.

- Maximum density of measurements and a continuous monitoring of EM emissions over seismic areas.

- Necessity to detect particles affected by EM emission waves of terrestrial origin and generated by seismotectonic processes: particle detector must skim LShells just beneath the inner radiation belts.

b. Model payload

- Multi-instrument payload to detect ULF through to HF electric and magnetic fields; ionospheric plasma temperature and density; particle fluxes, pitch angle, and energy.

- High instrumental sensitivity, signal-to-noise ratio, and dynamic range for all the parameters to be studied.

- Continuous data acquisition.

- No interaction and disturbances between different instruments.

- No differential photoemission from the external surface of platform and payload.

- No influence of electric field distortion in EM emissions measurements caused by the satellite metallic structure and geometry.

c. Ground-based measurements

- Seismic activity, coordinated and continuous preseismic mechanical (tilt and strain) and EM fields in test areas.

- Comparisons and integration of space observations with ground-based ones.

When the above-mentioned requirements are taken into account, and in particular the necessity to be inside the ionosphere-magnetosphere transition zone and to carry out a high-accuracy Earth's surface monitoring, it is necessary that the mission has a geo-synchronous magnetic equatorial orbit with an altitude between about 600 and $1000 \mathrm{~km}$ (topside ionosphere). To perform a high-accuracy ground monitoring, there is a requirement for a ground track repetition of a fixed (integer) number of orbits per day-i.e. by a fixed orbit altitude. To this end, a FEEP (Field Electric Emission propulsion) system is applied to the ESPERIA platform so that, if necessary, some changes in the orbit can also be adopted during the mission. For 14 orbits/day, the corresponding altitude will be $813 \mathrm{~km}$; therefore, a $L E O$ orbit is requested. This orbit altitude corresponds to a field of view of $\pm 39^{\circ}$ with a revisit time of $\leq 24 \mathrm{~h}$. Note that when the orbit has inclination $0^{\circ}$, the revisit time coincides with the orbit period $(110 \mathrm{~min})$. Moreover, the satellite trajectory oscillates around the magnetic equator up to geomagnetic latitudes of $\pm 23^{\circ}$. This condition guarantees an optimal detectability of particle bursts precipitating from the inner radiation belt as well as the further conditions of a good field of view and of a short revisit time giving rise to a good ground monitoring of local short-term earthquake precursor phenomena. The observation geometry implies nadir pointing.

In summary, all of the above-mentioned requirements and suggestions in terms of orbit, mission, spacecraft and payload instrument characteristics have been adopted for ESPERIA (Subsection 3.2).

\subsection{ESPERIA main features}

1. Orbit characteristics

- Ground track repetition with accuracy of $10 \mathrm{~km}$.

- Revisit time $\leq 24 \mathrm{~h}$; geosynchronous orbit: 14 orbits/day.

- Altitude $=813 \mathrm{~km} ;$ inclination $=11^{\circ} .5$, eccentricity $=0$; orbit period: $110 \mathrm{~min}$.

- Orbit knowledge and time resolution $\approx 100 \mathrm{~m}$ and $1 \mathrm{~s}$, respectively.

- Field of view: $\pm 39^{\circ}$.

- Maximum oscillation around the magnetic equator: $\pm 23^{\circ}$.

\section{Spacecraft}

- Platform MITA with Nadir pointing.

- FEEP thrusters applied to the platform (constant altitude).

3. Mission duration $\geq 2$ years

4. Payload instrument

a. Electric Field Analyser (EFA)

- frequency range: $\sim \mathrm{DC} \div 10 \mathrm{MHz}$

- accuracy: $300 \mathrm{nV} / \mathrm{m}$

- dynamic range: $120 \mathrm{~dB}$

b. Magnetic Field Analyser (MAFA)

○ FLUX-GATE:

- frequency range: $\sim \mathrm{DC} \div 10 \mathrm{~Hz}$

- accuracy: a few (6-8) pT; resolution: 24 bit

- SEARCH-COIL:

- frequency range: $\sim 10 \mathrm{~Hz} \div 100 \mathrm{kHz}$

- sensitivity: $10^{-2} \mathrm{pT} /(\mathrm{Hz})^{1 / 2}$ (at $1 \mathrm{kHz}$ )

c. Langmuir Probe (LP) \& Retarding Potential Analyser (RPA)

LP: electron temperature: $300 \div 15000 \mathrm{~K}$; electron density: $10^{2} \div 10^{7} \mathrm{~cm}^{-3}$

RPA: ionic temperature: $300 \div 10000 \mathrm{~K}$; ionic density: $10^{2} \div 10^{7} \mathrm{~cm}^{-3}$

d. Particle Detector Analyser (PDA)

Energy range: $300 \mathrm{KeV} \div 2 \mathrm{GeV}$

Pitch angle precision $<4^{\circ}$ with particle identification

Geometry: 5 silicon strip telescope +1 calorimeter

1 silicon strip telescope +1 calorimeter

An overview of the ESPERIA satellite illustrating the location of the different instruments of the scientific payload is given in Fig. 1. As can be seen, the PDA, LP, and RPA instruments are located at the top of the satellite. Each MAFA sensor system is at a different end of the two primary expanding booms (approx. $5 \mathrm{~m}$ ) so that searchcoils are separated by about $10 \mathrm{~m}$ from the flux-gate sensors and each sensor system is at a distance of about $5 \mathrm{~m}$ from the satellite body. Electric probes with preamplifiers inside are located at the end of the secondary booms (approx. $2 \mathrm{~m}$ ), so that each electric sensor system is about $2 \mathrm{~m}$ 


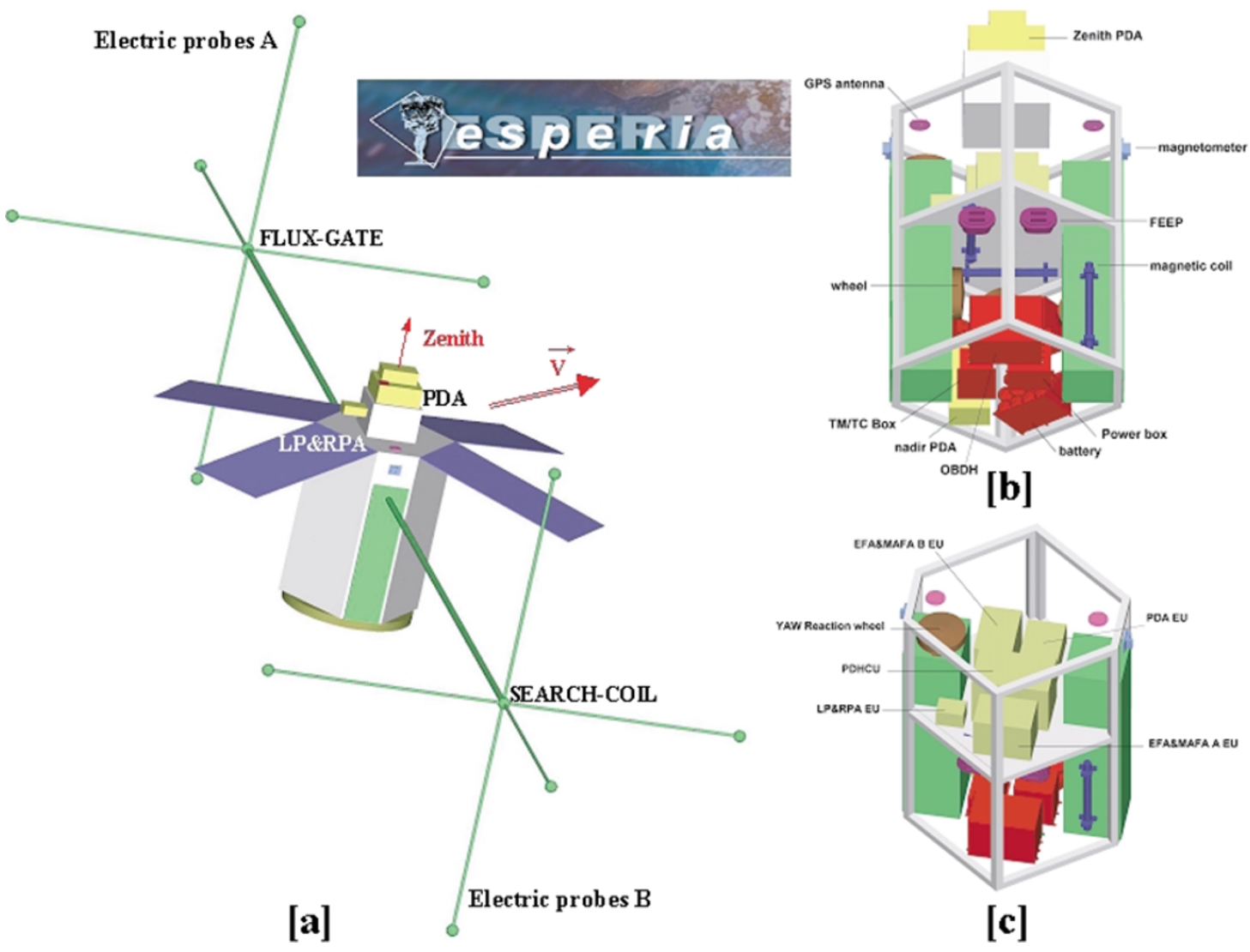

Fig. 1. (a) Schematic external view of the ESPERIA satellite with deployed booms and relative systems of antennas for electric (EFA) and magnetic (MAFA) field measurements. Particle detector (PDA), Plasma Langmuir probe and Retarding potential analyzer (LP\&RPA) as well as solar panels (top) are also shown. (b, c) ESPERIA Spacecraft internal configuration including the multi-instrument payload EFA/MAFA, PDA, and LP\&RPA, FEEP and other platform instruments.

from the nearest magnetic sensor system. Instead of magnetic torques, the attitude control is implemented by three reaction wheels (of known EM spectra). In this way, magnetic disturbances are less than $2 \mathrm{pT}$ at a distance of $5 \mathrm{~m}$ (deployed booms/magnetic probes accommodation), that is, magnetic disturbances are less than the instrumental sensitivity.

For EM cleanliness, all probes will be switched off during the de-saturation of the reaction wheels or when (for short periods) FEEP is active. To guarantee the electric equipotentiality of external satellite surfaces, we also planned a surface plating of the spacecraft and a special solar panels design. This will imply uniform electrical and optical characteristics of the external surfaces of the satellite, which are equal to that of electric EFA probe surfaces. The velocity vector of the satellite is perpendicular to the direction of primary booms.

ESPERIA was planned and designed by an International Consortium lead by the Roma Tre University of Rome (Vittorio Sgrigna, Principal Investigator). The first ESPERIA instruments (LAZIO-EGLE and ARINA) have already been launched in space (see Section 4).

\subsection{Relation with other missions and science teams}

ARINA (Subsection 4.2) and DEMETER (Parrot, 2002) are two simultaneous polar missions which allow comparisons of particle data within the DEMETER Guest Investigator Programme (Sgrigna et al., 2005b). ESPERIA may be considered as a second generation of the DEMETER concept and can profit by the information provided by previous missions. The equatorial character of ESPERIA and some augmentation or changes in its payload enable the original scientific objectives of this mission for geo-electric and magnetic field mapping to be extended to the study of sun activity and cosmic rays and an investigation of the structure and dynamics of the magnetospheric cavity.

\section{The EGLE and ARINA Space Experiments}

A few ESPERIA instruments (particle detectors LAZIO and ARINA and search-coil magnetometer EGLE) have been built and tested in space (Picozza, 2003; Sgrigna et al., 2005b).

EGLE was installed on board the International Space Station (ISS) on April 15, 2005, within the LAZIO-EGLE experiment of the ENEIDE mission, which has been coordinated by the European Space Agency (ESA) and received contributions from the Italian National Institute of Nuclear Physics (INFN) and Regione Lazio.

The launch of ARINA occurred on June 15, 2006 within the PAMELA mission. ARINA will perform particle measurements on a quasi-polar orbit RESURS DK-1 Russian LEO satellite.

ARINA particle data and EGLE magnetic data, together with fault creep events from the TELLUS ground tilt network of Central Italy and magnetic and EM data from 


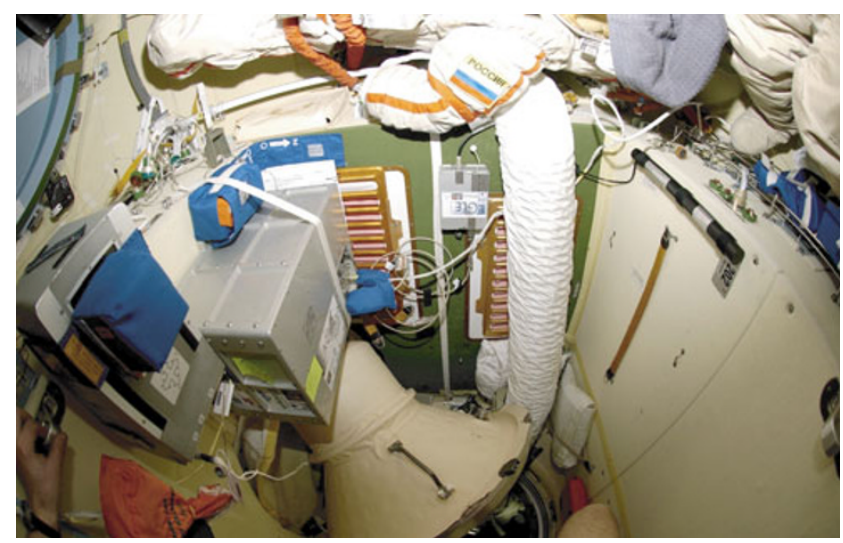

Fig. 2. Picture of LAZIO-EGLE inside the PIRS module of the ISS.

ground-based networks located in other countries, should also be available. All such data may be studied together with those obtained from DEMETER instruments, through the Demeter Guest Investigator Programme. A few preliminary indications on the analysis of DEMETER data and related theoretical modelling are reported in Section 5.

\subsection{The EGLE magnetic experiment on board the In-} ternational Space Station

The monitoring of the EM environment on board the ISS needs both an appropriate observation methodology and a corresponding experimental equipment design. The continuous monitoring of the EM environment on board the ISS by an advanced magnetic experiment in the ULF-HF band is important in the following areas:

a. Search of space weather conditions in equatorial, middle-latitude and sub-auroral ionosphere.

b. Geophysical research of plasma-wave processes connected to solar-magnetosphere-ionosphereatmosphere-lithosphere interactions.

c. Investigation of the possible relationships between seismic activity and ULF-VLF phenomena possibly related to earthquakes.

d. Continuous monitoring of ULF-ELF-VLF activity in the near-Earth space including ELF-VLF pollution.

e. Monitoring of natural and man-made variations of the plasma-sphere caused by whistlers.

f. Investigation of EM background and space weather phenomena.

g. Investigation of the effects of the large ISS structure on the propagating wave-front.

The LAZIO-EGLE experiment aims at performing measurements involving:

1. The radiation environment.

2. The magnetic environment inside the ISS.

The experiment includes the high-precision lowfrequency magnetometer EGLE (Esperia's Geomagnetometer for a Low-frequency wave Experiment).

EGLE is able to measure the intensity and variations in the magnetic field within the ISS and to correlate these measurements with those of particle fluxes. The study of these effects is important to detect electromagnetic field varia- tions and particle pitch angle distribution of the precipitating particles.

EGLE experiment is also the first test in space of a data

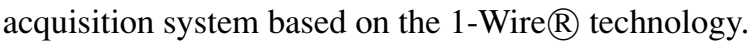

The EGLE magnetometer consists of:

- A single axis search coil probe, the EGLE Magnetometer Head (MH), which has been developed in collaboration with V. Korepanov of the Lviv Centre of Space Research.

- An electronic interface with amplifiers, filtering and data acquisition unit (EGLE MB box).

- A 2-m long cable to connect LAZIO MEB and EGLE $\mathrm{MB}$.

- A 1-Wire $\mathbb{R}$ to RS232 serial adapter on the LAZIO pc tower.

Magnetic field signals detected by the EGLE-MH probe are amplified, filtered and recorded by the EGLE acquisition and data handling board located in the EGLE-MB box. The EGLE magnetometer magnetic field data to be collected in four frequency bands (DC through to $20 \mathrm{~Hz}$ raw data; $0.5-40 \mathrm{~Hz} ; 500 \mathrm{~Hz}-5 \mathrm{kHz} ; 20-40 \mathrm{kHz}$ integrated r.m.s. data).

Gaps between these frequency ranges have been chosen to filter well-known spurious artificial signals produced inside ISS.

The advantages of using EGLE device are:

- High-accuracy measurements.

- Small dimensions and mass.

- Low power consumption.

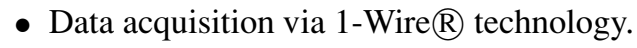

- A standard ISS power supply of the device.

The peculiar characteristic of the 1-Wire $\mathbb{R}$ technology prompted us to use it in the EGLE experiment to test its possible application in satellite EM measurements where the necessity to hold magnetic sensors far from the satellite body by expanding booms is an important factor for magnetic cleanness (see architecture of electric and magnetic probes in the ESPERIA payload). In fact, the use of 1 -Wire $\mathbb{R}$ technology can strongly reduce the numbers of wires necessary to connect many remote magnetic and electric probes (necessary in these types of investigations) with the central electronic unit located in the satellite body.

Figure 2 depicts the LAZIO-EGLE installation inside the PIRS section of the ISS. As can be seen, MEB (left), EGLEMB (front) and EGLE-MH (right) are fixed by velcro tags to the ISS wall. The characteristic frequency response of the EGLE probe is reported in Fig. 3. An example of data recorded on board ISS is shown in Fig. 4.

As it can be seen, part of the ULF frequency band can also be detected by this sensor. This is an unusual characteristic for a search-coil probe and characterizes EGLE as an original broad-band magnetometer, which in a few satellite applications can allow a significant mass reduction by avoiding the use of flux-gate sensors.

\subsection{The ARINA particle experiment on board a LEO} Satellite

The ARINA experiment consists of a proton-electron telescope to be installed on board the polar LEO Russian 

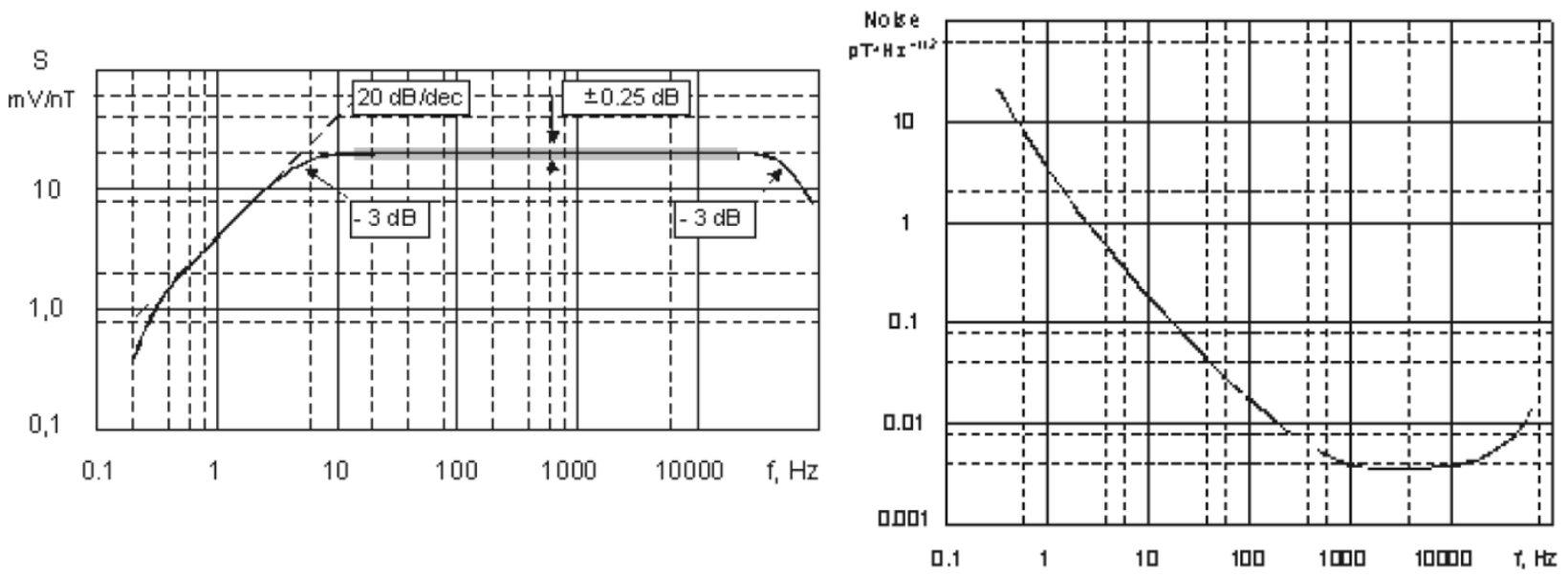

Fig. 3. Frequency response (left) and noise spectral density (right) of EGLE search-coil magnetometer.

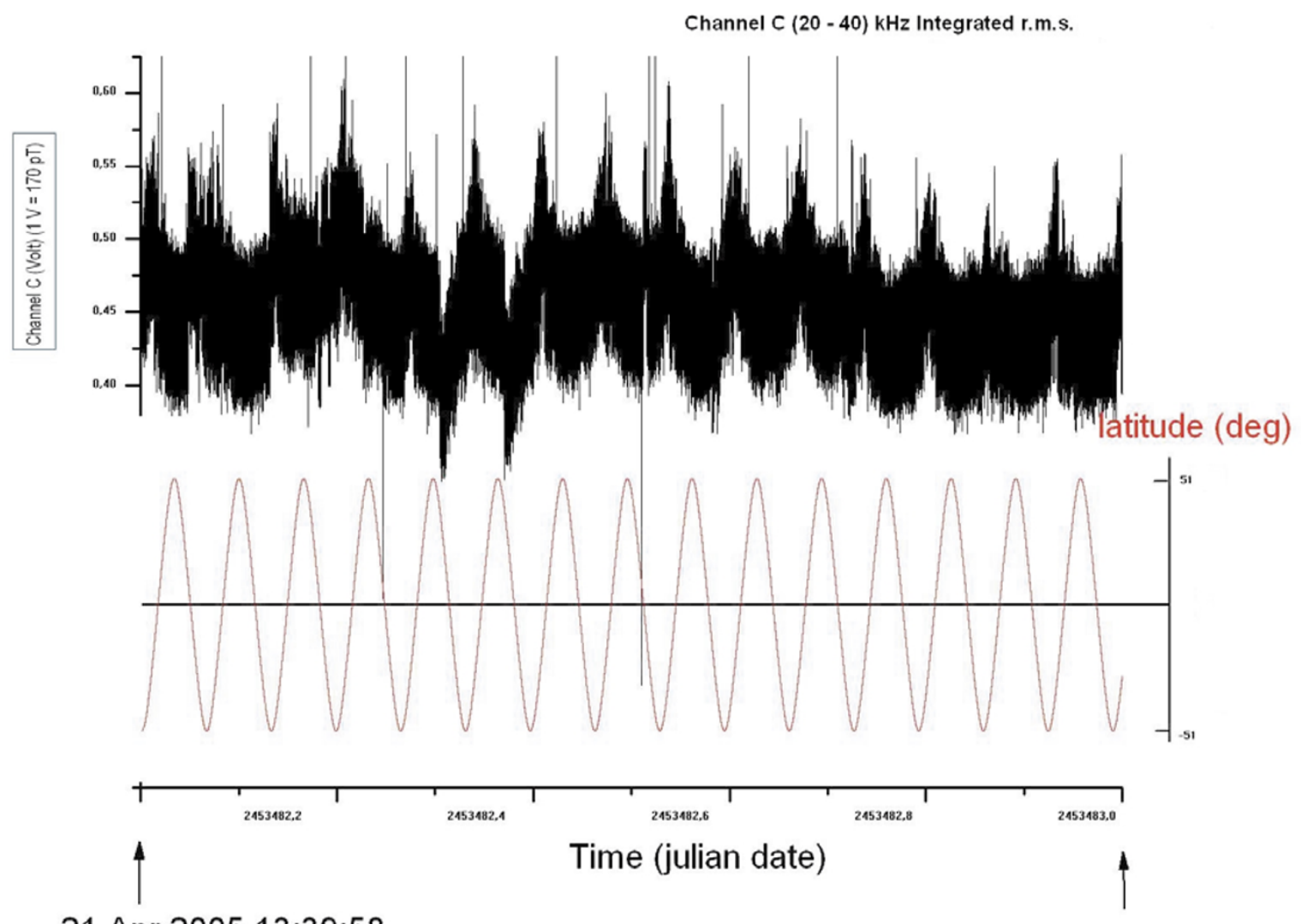

21 Apr 2005 13:39:58

22 Apr 2005 12:49:21

Fig. 4. An example of magnetic data in the frequency band (20-40) kHz, recorded by EGLE on board the ISS. Magnetic signal is compared with contemporary latitude variation of the ISS.

satellite RESURS-DK1 within the PAMELA mission. The orbit is elliptic, with an altitude ranging from 300 to $600 \mathrm{~km}$ and an inclination of $70.4^{\circ}$. The duration of the mission will be $\geq 3$ years. The scientific objective of the experiment is to detect fluxes of high-energy charged particles $(3 \div 100 \mathrm{MeV})$, from the inner radiation belt and correlate them with seismic activity.

The main features of the ARINA instrument are reported in Fig. 5. As can be seen from this figure, the instrument consists of a set of scintillation detectors $\mathrm{C} 1-\mathrm{C} 12$ made on the basis of polystyrene, which are viewed by photomultipliers (PMTs), the event recording system, the data acquisition and processing system (DAPS), the power supply system (PSS) and the command unit (CU). Detectors C1$\mathrm{C} 12$ are functionally combined into three systems: the hodoscopic trigger system HTS (detectors C1-C3), the scintillation calorimeter SC (detectors $\mathrm{C} 4-\mathrm{C} 9$ ) and the anticoincidence system ACS (detectors $\mathrm{C} 10-\mathrm{C} 12$ ). Each of the detectors $\mathrm{C} 1$ and $\mathrm{C} 2$ consists of four strips directed perpendicularly and positioned just one under another. Detector 

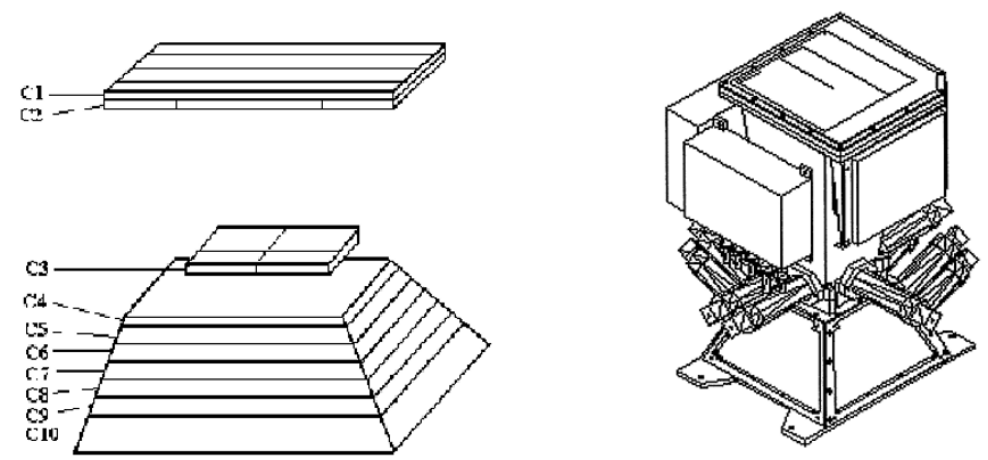

C1-C3: Trigger coincidence scintillation telescope

C4-C10: Scintillation calorimeter

C11-C12: Scintillation anticoincidence detectors

Fig. 5. ARINA space instrument layout.
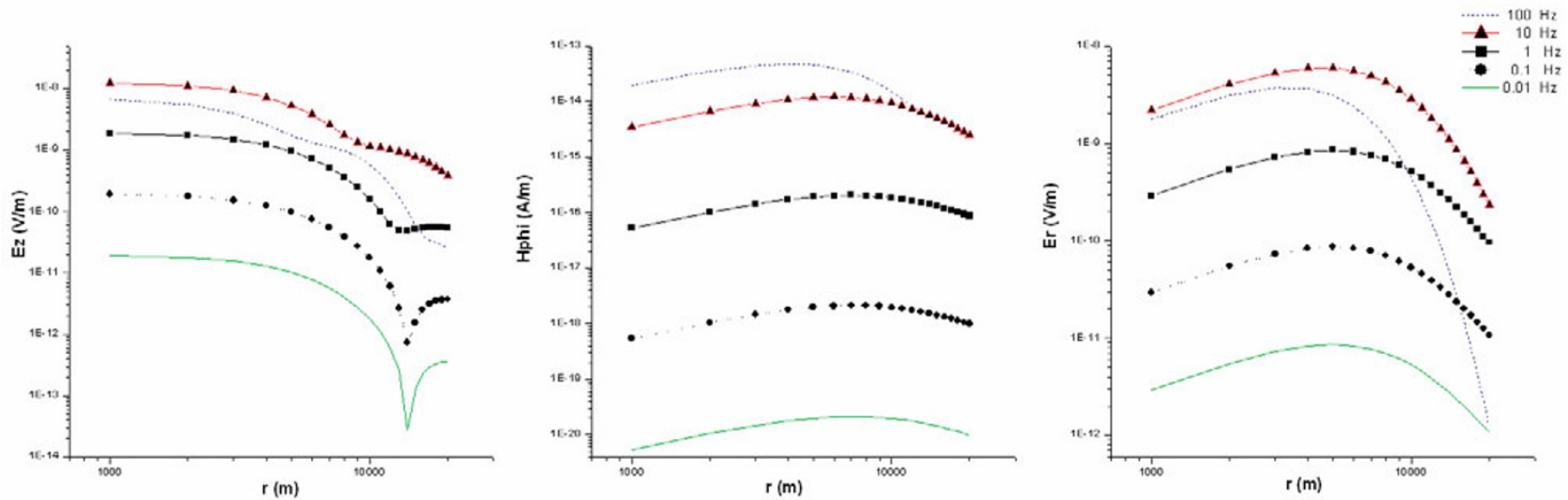

Fig. 6. Electric and magnetic field components radiated by a point-like buried electric vertical dipole located at hypocentral depth of $10 \mathrm{~km}$ for a two-layer model (lithospheric and atmospheric ones). The electric and magnetic field components are plotted as a function of radial distance from a point on the Earth surface located above the dipole position, and for frequencies ranging from 0.01 to $100 \mathrm{~Hz}$ (ULF-ELF frequency bands).

C3 is situated below detectors $\mathrm{C} 1$ and $\mathrm{C} 2$ and has a mosaic structure (six elements). Each mosaic element is viewed by its own PMT. This type of assembly enables the angle of incident particle to be determined. The geometry and dimensions of detectors $\mathrm{C} 1-\mathrm{C} 3$ define the instrument aperture and the geometric factor. The scintillation calorimeter can comprise the detector $\mathrm{C} 3$ in addition to another set of detectors, $\mathrm{C} 4-\mathrm{C} 9$. It provides the separation of the protons and electrons and enables the particle energy to be measured by the number of detectors, passed by the particle up to its stop; that is, it is used the range of the particle in the stack of detectors. The ACS consists of the detector C10 and lateral detectors $\mathrm{C} 11$ and $\mathrm{C} 12$, and it is needed to exclude the particles moving in the opposite direction ("from the bottom to upward") from being recorded as well as all directions beyond the aperture.

\section{Work in Progress about SEME Theoretical Modeling and DEMETER Data Processing}

Using data collected by the DEMETER mission and within the CNES guest investigator programme, we have been carried out preliminary attempts on investigating possible effects of seismicity on the occurrence of anomalous whistlers and on the precipitation of particle fluxes from the inner Van Allen radiation belt (Conti et al., 2007; Buzzi et al., 2006). Results are at a very preliminary stage and await confirmation and discussions with our French colleagues of the LPCE/CNRS DEMETER team in Orleans lead by Michel Parrot.

There seems to be a spatial and temporal correlation between earthquakes and whistlers. Although some aspects of DEMETER whistler class distribution have to be clarified, in the presence of high whistler dispersion values, the number of whistlers close to earthquakes and conjugation points exhibits a greater increase than those detected along the magnetic field line (Buzzi et al., 2007; Conti et al., 2007). This area of research is still under study, and results must to be validated that extend the analysis to larger time windows and refine selection criteria.

We propose a model to describe the propagation of preseismic EME from the preparation focal area of an earthquake to the near-Earth space. Two seismo-electromagnetic sources have been considered. The first one is a pointlike source constituted by electric or magnetic oscillating dipoles with vertical and horizontal orientations. The second one is a more realistic volumetric source, based on clas- 
sic dilatancy models; it is represented by a spatial distribution of elementary emitters filling the source volume. The model describes the propagation of electric and magnetic fields through layered lithospheric and atmospheric media with assigned vertical conductivity profiles. Lithospheric and atmospheric layers have been assumed on a realistic basis as well as the associated characteristic physical parameters. No constrains have been applied a priori to the frequency spectrum of the electromagnetic source in order to determine the real attenuation of electromagnetic waves caused by the conductive layers. The model allows the electric and magnetic fields in each layer to be determined.

As an example, Fig. 6 shows the results of electric and magnetic field components radiated by a point-like buried electric vertical dipole buried at the hypocentral depth for a two-layer model (lithospheric and atmospheric ones). The electric and magnetic field components are plotted as a function of radial distance from a point on the surface directly above the dipole position for frequencies from 0.01 up to $100 \mathrm{~Hz}$. Electric dipole intensity is defined by fixing directly the $p_{0}=q l$ charge-distance product instead of using the dipole electric current value. Data reported in Fig. 6 are for an unitary intensity dipole. Lithospheric and atmospheric electric conductivity values have been fixed at $10^{-3} \mathrm{~S} / \mathrm{m}$ and $10^{-14} \mathrm{~S} / \mathrm{m}$, respectively. Electric permittivity is $10 \varepsilon_{0}$ and $1 \varepsilon_{0}$ in the lithospheric and atmospheric layers, respectively.

A strong decrease of the electric and magnetic field components with distance can be seen in the figure. Due to the fixed value for the charge-distance product $\left(p_{0}=q l\right)$, instead of the dipole electric current value, both electric and magnetic field components versus frequency increase at a given distance. In contrast, the electric horizontal and vertical components $\left(E_{r}\right.$ and $\left.E_{z}\right)$ decrease for frequency values greater than $10 \mathrm{~Hz}$. It can also be seen that, particularly at low-frequency values, the intensity of the electric vertical component $\left(E_{z}\right)$ at a distance of approximately $(10 \div 11) \mathrm{km}$ is lower than that at greater distances. Due to this behavior, there are some areas near the epicentral zone where the detectability of the vertical electric field intensity is unexpectedly lower than that estimated at higher distances. These aspects are still under study.

\section{Conclusions and Outlook}

EM emissions radiated from the Earth's surface and produced as a consequence of earthquake preparation and occurrence, or by human activities, are demonstrated to cause ionospheric perturbations that are detectable by $L E O$ satellites. Within this framework, we describe the ESPERIA satellite project designed for detecting seismo-associated effects in the topside ionosphere and first ESPERIA instruments (LAZIO-EGLE and ARINA), which have been tested in space on the occasion of the ENEIDE and PAMELA missions on board the ISS and Resurs-DK1 satellite, respectively.

We have clarified different methodological aspects on damage prevention and prediction approaches used to defend society from such destructive events as earthquakes and provided and a short summary of the scientific background of ground and space observations on earthquake precursors together with relative first theoretical interpretations.

Finally, we will be reporting the first indications from the DEMETER whistler data analysis and theoretical modeling of electric and magnetic fields propagation from the lithosphere to the ionosphere in the near future. This part of the work is still in progress.

\section{References}

Areshidze, G., F. Bella, P. F. Biagi, M. Caputo, V. Chkuaseli, G. Della Monica, A. Ermini, P. Manjgaladze, G. Melikadze, V. Sgrigna, L. Slavina, and D. Zilpimiani, Anomalies in geophysical and geochemical parameters revealed in the occasion of the Paravani $(M=5.6)$ and Spitak ( $M=6.9$ ) earthquakes (Caucasus), Tectonophysics, 202, 23-41, 1992.

Aleksandrin, S. Yu., A. M. Galper, L. A. Grishantzeva, S. V. Koldashov, L. V. Maslennikov, A. M. Murashov, P. Picozza, V. Sgrigna, and S. A. Voronov, High-energy charged particle bursts in the near-Earth space as earthquake precursors, Ann. Geophys., 21, 597-602, 2003.

Aleshina, M. E., S. A. Voronov, A. M. Galper, S. V. Koldashov, and L. V. Maslennikov, Correlation between Earthquake Epicenters and Regions of High-Energy Particle Precipitations from the Radiation Belt, Cosmic Res., 30(1), 79-83, 1992.

Bella, F., R. Bella, P. F. Biagi, A. Ermini, and V. Sgrigna, Possible precursory tilts preceding some earthquakes $(3.0 \leq M \leq 3.8)$ occurred in Central Italy between February 1981 and June 1983, Earthq. Predict. Res., 4, 147-154, 1986a.

Bella, F., P. F. Biagi, A. Ermini, V. Sgrigna, and P. Manjgaladze, Possible Propagation of Tilt and Strain Anomalies: Velocity and other Characteristics, Earthq. Predict. Res., 4, 195-209, 1986b.

Bella, F., P. F. Biagi, M. Caputo, G. Della Monica, A. Ermini, and V. Sgrigna, Very slow-moving Crustal Strain Disturbances, Tectonophysics, 179, 131-139, 1990.

Bella, F., P. F. Biagi, M. Caputo, G. Della Monica, A. Ermini, and V. Sgrigna, Ground Tilt Anomalies Accompanying the Main Earthquakes Occurred in the Central Apennines (Italy) during the Period 1986-1989, Nuovo Cimento, 16C, 393-406, 1993.

Bella, F., P. F. Biagi, M. Caputo, G. Della Monica, A. Ermini, P. V. Manjgaladze, V. Sgrigna, and D. O. Zilpimiani, Possible Creep-related Tilt Precursors Obtained in the Central Apennines (Italy) and in the Southern Caucasus (Geirgia), Pure Appl. Geophys., 144, 277-299, 1995.

Bella, F., M. Caputo, G. Della Monica, A. Lisi, W. Plastino, R. Scandone, and V. Sgrigna, Crustal Blocks and Seismicity in the Central Apennines of Italy, Nuovo Cimento, 21C, 597-607, 1998.

Bernabé, Y., Streaming potential in heterogeneous network, J. Geophys. Res., 103, 20827-20841, 1998.

Bilham, R. G., Delays in the Onset Times of Near-Surface Strain and Tilt Precursor to Earthquakes, in Earthquake Prediction: An International Review, edited by P. J. Simpson and P. G. Richards, pp. 411-421, Geophysical Union, Washington, D.C. 1981, 1981.

Bilham, R. G. and R. J. Beavan, Strains and tilts on crustal blocks, Tectonophysics, 52, 121-138, 1979.

Bilham, R. G., J. Beavan, K. Evans, and K. Hurst, Crustal deformation metrology at Lamont-Doherty Geological Observatory, Earthq. Predict. Res., 3, 391-411, 1985.

Bilichenko, S. V., F. S. Iljin, E. F. Kim, O. A. Pokhotelov, P. P. Puschaev, G. A. Stanev, A. V. Streltsov, and V. M. Chmyrev, ULF response of the ionosphere for earthquake preparation processes, Dokl. Acad. Nauk, USSR, 311, 1077-1080, 1990.

Bishop, J. R., Piezoelectric effects in quartz-rich rocks, Tectonophysics, 77, 297-321, 1981.

Blanc, E., Observations in the upper atmosphere of infrasonic waves from natural or artificial sources: a summary, Ann. Geophys., 3(6), 673-688, 1985.

Buzzi, A., M. Parrot, and J. A. Sauvaud, Precipitation of particles by intense electromagnetic harmonic waves during magnetic storms, Comunication to the Conference "Symposium International Déméter" (Toulouse, France, 14-16 Giugno 2006).

Buzzi, A., L. Conti, M. Parrot, J. L. Pincon, V. Sgrigna, and Z. Zilpimiani, Statistical study of anomalous fluctuations of whistler data recorded by DEMETER, 2007 IUGG XXIV General Assembly, IAGA-IASPEIIAVCEI Joint Section "JSS010: Progress in electromagnetic studies on earthquakes and volcanoes-Seismo-electromagnetic studies using space technology", Abstr. 10032, Perugia, Italy, July 2-13, 2007.

Chmyrev, V. M., N. V. Isaev, O. N. Serebryakova, V. M. Sorokin, and 
Ya. P. Sobolev, Small-scale plasma inhomogeneities and correlated ELF emissions in the ionosphere over an earthquake region, J. Atm. SolarTerr. Phys., 59, 967-974, 1997.

Conti, L., A. Buzzi, A. M. Galper, S. V. Koldashov, A. M. Murashov, P. Picozza, R. Scrimaglio, V. Sgrigna, and L. Stagni, Influence of the seismic activity on the inner Van Allen radiation belt, 10th Scientific Assembly of the International Association of Geomagnetism and Aeronomy (IAGA 2005), Toulose, France, July 18-29, 2005, Session Division I, GA101: Monitoring earthquakes and volcanic activity by magnetic, electric and electromagnetic methods; IAGA2005-A-01518, p. 46, 2005 .

Conti, L., A. Buzzi, M. Parrot, J. L. Pincon, V. Sgrigna, and Z. Zilpimiani, Possible influence of seismic activity on the propagation of anomalous whistlers recorded in space, 2007 IUGG XXIV General Assembly, IAGA-IASPEI-IAVCEI Joint Section “JSS010: Progress in electromagnetic studies on earthquakes and volcanoes-Seismo-electromagnetic studies using space technology", Abstr. 10093, Perugia, Italy, July 2 13, 2007.

Dobrovolsky, I. P., N. I. Gershenzon, and M. B. Gokhberg, Theory of electrokinetic effects occurring at the final stage in the preparation of a tectonic earthquake, Phys. Earth Planet. Inter., 57, 144-156, 1989.

Draganov, A. B., U. S. Inan, and Y. N. Taranenko, ULF magnetic signatures at the Earth surface due to the ground water flow: a possible precursor to earthquakes, Geophys. Res. Lett., 18, 1127-1130, 1991.

Eftaxias, K., P. Kapiris, J. Polygiannakis, A. Peratzakis, J. Kopanas, G. Antonopoulos, and D. Rigas, Experience of short term earthquake precursors with VLF-VHF electromagnetic emissions, Nat. Hazard Earth Syst. Sci., 3, 217-228, 2003.

Fenoglio, M. A., M. J. S. Johnston, and J. D. Byerlee, Magnetic and electric fields associated with changes in high pore pressure in fault zones: application to the Loma Prieta ULF emissions, J. Geophys. Res., 100, 12951-12958, 1995.

Fraser-Smith, A. C., P. R. McGill, R. A. Helliwell, and O. G. Villard, Jr., Ultra-low frequency magnetic field measurements in southern California during the Northridge earthquake of 17 January 1994, Geophys. Res. Lett., 21, 2195-2198, 1994.

Freund, F. T., Charge generation and propagation in igneous rocks, $J$. Geodyn., 33, 543-570, 2002.

Freund, F. T., On the electrical conductivity structure of the stable continental crust, J. Geodyn., 35, 353-388, 2003.

Freund, F. T., A. Takeushi, and B. W. S. Lau, Electric currents streamimg out of stressed igneous rocks-A step towards understanding preearthquake low frequency EM emissions, Phys. Chem. Earth, 31, 389396, 2006.

Fujinawa, Y., K. Takahashi, and T. Matsumoto, Modeling confined pressure changes inducing anomalous electromagnetic fields related with earthquakes, J. Appl. Geophys., 49, 101-110, 2002.

Fujiwara, H., M. Kamogawa, M. Ikeda, Y. J. Liu, H. Sakata, Y. I. Chen, H. Ofuruton, S. Muramatsu, Y. J. Chuo, and Y. H. Ohtsuki, Atmospheric anomalies observed during earthquake occurrences, Geophys. Res. Lett., 31, L17110, doi: 10.1029/2004GL019865, 2004.

Gabrielov, A. M., T. A. Levshina, and I. M. Rotwain, Block model of earthquake sequence, Phys. Earth Planet. Inter., 61, 18-22, 1990.

Galli, I., Raccolta e classificazione di fenomeni luminosi osservati nei terremoti, Boll. Soc. Ital. Sismologia, n.14, 1910.

Galper, A. M., V. B. Dimitrenko, N. V. Nikitina, V. M. Grachev, and S. E. Ulin, Interrelation between High-Energy Charged Particle Fluxes in the Radiation Belt and Seismicity of the Earth, Cosmic Res., 27, 789, 1989.

Galper, A. M., S. V. Koldashov, and S. A. Voronov, High energy particle flux variations as earthquake predictors, Adv. Space Res., 15, 131-134, 1995.

Galperin, Yu. I., V. A. Gladyshev, N. V. Jordjio, and V. I. Larkina, Precipitation of High-Energy Captured Particles in the Magnetosphere Above the Epicenter of an Incipient Earthquake, Cosmic Res., 30, 89-106, 1992.

Geller, R. J., Debate on VAN, Geophys. Res. Lett., 23 (whole issue 11), 1996.

Gershenzon, N. and G. Bambakidis, Modeling of seismo-electromagnetic phenomena, Russ. J. Earth Sci., 3, 247-275, 2001.

Ginzburg, E. A., A. B. Malishev, I. P. Proshkina, and V. P. Pustovetov, Correlation of strong earthquakes with radiation belt particle flux variations, Geomagn. Aeron. (Engl. Transl.), 34, 315-320, 1994.

Gokhberg, M. B., V. A. Morgounov, and E. L. Aronov, On the high frequency electromagnetic radiation during seismic activity, Dokladi Acad. Sci. USSR, 248, 1077-1081, 1979.

Grimalsky, V. V., I. A. Kremenetsky, and Yu. G. Rapoport, Excitation of EMW in the Lithosphere and Propagation into Magnetosphere, in Atmospheric and Ionospheric Electromagnetic Phenomena Associated with Earthquakes, edited by M. Hayakawa, pp. 777-787, TERRAPUB, Tokyo, 1999.

Gufeld, I., G. Gusev, and O. Pokhotelov, Is the prediction of earthquake dates possible by the VLF radiowave monitoring method?, in Electromagnetic Phenomena Related to Earthquake Prediction, edited by $\mathrm{M}$ Hayakawa and Y. Fujinawa, pp. 381-389, TERRAPUB, Tokyo, 1994.

Guo, Z., B. Liu, and Y. Wang, Mechanism of electromagnetic emissions associated with microscopic and macroscopic cracking in rocks, in Electromagnetic Phenomena Related to Earthquake Prediction, edited by M. Hayakawa, pp. 523-529, TERRAPUB, Tokyo, 1994.

Hayakawa, M. and H. Sato, Ionospheric perturbations associated with earthquakes, as detected by subionospheric VLF propagation, in Electromagnetic Phenomena Related to Earthquake Prediction, edited by M Hayakawa and Y. Fujinawa, pp. 391-397, TERRAPUB, Tokyo, 1994.

Hayakawa, M., Yu. Kopytenko, N. Smirnova, V. Troyan, and Th. Peterson, Monitoring ULF magnetic disturbances and schemes for recognizing earthquake precursors, Phys. Chem. Earth (A), 25, 263-269, 2000.

Hayakawa, M., O. A. Molchanov, and A. P. Nikolaenko, Model variations in atmospheric radio noise caused by preseismic modifications of tropospheric conductivity profile, in Seismo Electromagnetics: LithosphereAtmosphere-Ionosphere Coupling, edited by M. Hayakawa and O. A. Molchanov, pp. 349-352, TERRAPUB, Tokyo, 2002.

Ida, Y., Slow moving deformation pulses along tectonic faults, Phys. Earth Planet. Inter., 9, 328-337, 1974.

Ismaguilov, V. S., Yu. A. Kopytenko, K. Hattori, P. M. Voronov, O. A Molchanov, and M. Hayakawa, ULF magnetic emissions connected with under sea bottom earthquakes, Nat. Hazard Earth Syst. Sci., 1, 23 31, 2001.

Johnston, M. J. S., Review of electric and magnetic fields accompanying seismic and volcanic activity, Surv. Geophys., 18, 441-475, 1997.

Johnston, M. J. S. and R. J. Mueller, Seismomagnetic observations during the 8 July 1986 magnitude 5.9 North Palm Springs earthquake, Science, 237, 1201-1203, 1987.

Keilis Borok, V. I., Intermediate term earthquake prediction, Proc. Natl. Acad. Sci. USA., 93, 3748-3755, 1996.

Keilis Borok, V. I. and A. Soloviev, Non Linear Dynamics of the Lithosphere and Earthquake Prediction, Springer, Berlin, 2003.

Kopytenko, Yu. A., T. G. Matiashvili, P. M. Voronov, E. A. Kopytenko, and O. A. Molchanov, Detection of ultra-low-frequency emissions connected with the Spitak earthquake and its aftershock activity, based on geomagnetic pulsations data at Dusheti and Vardzia observatories, Phys. Earth Planet. Inter., 77, 85-95, 1993.

Krechetov, V. V., Cerenkov radiation of protons in the magnetosphere as a source of VLF waves preceding an earthquake, Geomag. and Aeron. (Engl Transl.), 35, 688-691, 1996.

Larkina, V. I., V. V. Migulin, O. A. Molchanov, I. P. Kharkov, A. S. Inchin, and V. V. Schvetsova, Some statistical results on very low frequency radiowave emissions in the upper ionosphere over earthquake zones, Phys. Earth Planet. Inter., 57, 100-109, 1989.

Lee, C. C., J. Y. Liu, and C. J. Pan, The height of sporadic-E layer simultaneously observed by the VHF radar and ionosondes in Chung-Li, Geophys. Res. Lett., 27, 641-644, 2000.

Liu, J. Y., Y. I. Chen, Y. J. Chuo, and C. S. Chen, A statistical investigation of pre-earthquake ionospheric anomaly, J. Geophys. Res., 111, A05304, doi:10.1029/2005JA011333, 2006.

Long, M., A. Lorenz, G. Rodgers, E. Tapio, G. Tran, K. Jackson, R. Twiggs, and T. Bleier, A Cubesat derived design for a unique academic research mission in earthquake signature detection, in Proceedings of the 16th Annual/USU Conference on Small Satellites, Logan, Utah, August 2002, SSC02-IX-6, pp. 1-17, 2002.

McHugh, S. and M. J. S. Johnston, A Review of Observations and Dislocation Modeling of some Creep-Related Tilt Perturbations from Central California, in Terrestrial and Space Techniques in earthquake Prediction, edited by A. Vogel, (Vieweg and Sohn, Braunschweig, Wiesbaden 1979), pp. 181-201, 1979.

Merzer, M. and S. L. Klemperer, Modeling low-frequency magnetic-field precursors to the Loma Prieta earthquake with a precursory increase in fault-zone conductivity, Pure Appl. Geophys., 150, 217-248, 1997.

Molchanov, O. A., O. A. Mazhaeva, A. N. Golyavin, and M. Hayakawa, Observation by the Intercosmos-24 satellite of ELF-VLF electromagnetic emissions associated with earthquakes, Ann. Geophys., 11, 431440, 1993.

Molchanov, O. A., M. Hayakawa, and V. A. Rafalsky, Penetration Characteristics of Electromagnetic Emissions from an Underground Seismic 
Source into the Atmosphere, Ionosphere and Magnetosphere, J. Geophys. Res., 100, 1691-1712, 1995.

Molchanov, O. A. and M. Hayakawa, On the Generation Mechanism of ULF seismogenic Electromagnetic Emissions, Phys. Earth Planet. Inter., 105, 201-210, 1998.

Morgounov, V. A., T. Ondoh, and S. Nagai, Anomalous variation of VLF signals associated with strong earthquakes $M \geq 7.0$, in Electromagnetic Phenomena Related to Earthquake Prediction, edited by M. Hayakawa and Y. Fujinawa, pp. 409-428, TERRAPUB, Tokyo, 1994

Mortensen, C. E. and M. J. S. Johnston, The nature of surface tilt along 85 $\mathrm{km}$ of the San Andreas fault: preliminary results from a 14-instrument array, Pure Appl. Geophys, 113, 237-249, 1975.

Nardi, A. and M. Caputo, Perspective electric earthquake precursors observed in the Apennines, Eighth Workshop on Non Linear Dynamics and Earthquake Prediction, ICTP, SMR.1676-20, Trieste, 03-15 October 2005. Also in: Boll. Geofis. Teorica Appl., 47, 3-12, 2006.

Nomikos, K., F. Vallianatos, Kaliakatsos, S. Sideris, and M. Bakatsakis, Latest aspects of telluric and electromagnetic variations associated with shallow and intermediate depth earthquakes in South Aegean, Ann. Geofis., XL, 361-374, 1997.

Nur, A. M., H. Ron, and O. Scotti, Fault Mechanisms and the Kinematics of Block rotation, Geology, 14, 746-749, 1986.

Ohta, K., K. Umeda, N. Watanabe, and M. Hayakawa, ULF/ELF emissions observed in Japan, possibly associated with the Chi-Chi earthquake in Taiwan, Nat. Hazard Earth Syst. Sci., 1, 37-42, 2001.

Oike, K. and T. Ogawa, Electromagnetic radiations from shallow earthquake observed in the LF range, J. Geomag. Geoelectr., 38, 1031-1040, 1986.

Park, S. K., M. J. S. Johnston, T. R. Madden, F. D. Morgan, and H. F. Morrison, Electromagnetic precursors to earthquakes in the ULF band: a review of observations and mechanisms, Rev. Geophys., 31, 117-132, 1993.

Parrot, M., Statistical study of ELF/VLF emissions recorded by a lowaltitude satellite during seismic events, J. Geophys. Res., 99, 2333923347, 1994.

Parrot, M., The micro-satellite DEMETER, J. Geodyn., 33, 535-541, 2002.

Parrot, M. and M. M. Mogilevsky, VLF emissions associated with earthquakes and observed in the ionosphere and the magnetosphere, Phys. Earth Planet. Inter., 57, 86-99, 1989.

Parrot, M., J. Achache, J. J. Berthelier, E. Blanc, A. Deschamps, F. Lefeuvre, M. Menvielle, J. L. Plantet, P. Tarits, and J. P. Villain, High Frequency seismo-electromagnetic effects, Phys. Earth Planet. Inter., 77, 65-83, 1993.

Peresan, A., V. Kossobokov, L. Romashkova, and G. F. Panza, Intermediate-term middel-range earthquake prediction in Italy: a review, Earth Sci.Rev., 69, 97, 2005.

Pevnev, A. K., Earthquake prediction: geodetic aspects of the problem, Izv. Akad. Nauk SSSR, Fizika Zemli, 12, 88-98, 1988.

Pevnev, A. K., Deterministic geodetic prediction of preparation areas of strong crustal earthquakes, Earthquake prediction, Dushanbe, Donish, 11, 11-23, 1989

Picozza, P. (PAMELA/ARINA collaboration), The PAMELA MISSION, http://wizard.roma2.infn.it/pamela/index.htm, 2003.

Pulinets, S. A., Space Technologies for short-term earthquake warning, Adv. Space Res., 37, 643-652, 2006.

Pulinets, S. A., K. A. Boyarchuk, V. V. Hegai, V. P. Kim, and A. M. Lomonosov, Quasi-electrostatic model of atmosphere-thermosphereionosphere coupling, Adv. Space Res., 26, 1209-1218, 2000.

Pustovetov, V. P. and A. B. Malyshev, Space-Time Correlation of Earthquakes and High-Energy Particle Flux Variations in the Inner Radiation Belt, Cosmic Res., 31, 84-90, 1993.

Rodger, C. J., R. L. Dowden, and N. R. Thomson, Observations of Electromagnetic Activity Associated with Earthquakes by Low-Altitude Satellites, in Atmospheric and Ionospheric Electromagnetic Phenomena Associated with Earthquakes, edited by M. Hayakawa, pp. 697-710, TERRAPUB, Tokyo, 1999

Salvini, F., Block tectonics in Thin-skin Style-deformed regions: Examples from Structural Data in the Central Apennines, Ann. Geofis., XXXVI, 97-109, 1993.

Serebryakova, O. N., S. V. Bilichenko, V. M. Chmyrev, M. Parrot, J. L. Rauch, F. Lefeuvre, and O. A. Pokhotelov, Electromagnetic ELF radiation from earthquake regions as observed by low-altitude satellite, Geophys. Res. Lett., 19, 91-94, 1992.

Sgrigna, V. (Principal Investigator), Esperia Science Team, ESPERIA Phase A Report, Italian Space Agency (ASI), Program for Scientific
Missions dedicated to Earth Sciences, Rome, July 2001, pp. 194, 2001. Sgrigna, V. and V. Malvezzi, Preseismic creep strains revealed by ground tilt measurements in central Italy on the occasion of the 1997 UmbriaMarche Apennines earthquake sequence, Pure Appl. Geophys., 160, 1493-1515, 2003.

Sgrigna, V., R. Console, L. Conti, A. Galper, V. Malvezzi, M. Parrot, P. Picozza, R. Scrimaglio, P. Spillantini, and D. Zilpimiani, Preseismic Natural Emissions from the Earth's Surface and their effects in the near Earth Space, A project for monitoring Earthquakes from Space, EOS Trans., $A G U, \mathbf{8 3}, \mathrm{T} 22 \mathrm{~B}-10, \mathrm{n} .19, \mathrm{~S} 356,2002 \mathrm{a}$.

Sgrigna, V., C. D'ambrosio, and T. B. Yanovskaya, Numerical modeling of preseismic slow movements of crustal blocks caused by quasihorizontal tectonic forces, Phys. Earth Planet. Inter., 129, 313-324, $2002 b$.

Sgrigna, V., L. Carota, L. Conti, M. Corsi, A. Galper, P. Picozza, and L. Stagni, Correlations between earthquakes and anomalous particle bursts from SAMPEX/PET satellite observations, J. Atm. Solar-Terrestrial Phys., 67, 1448-1462, 2005a.

Sgrigna, V., Description and Testing of ARINA and LAZIO/EGLE instruments in Space within the ESPERIA mission project and the DEMETER Guest Investigation Programme. DEMETER Guest Investigator Workshop, CNES, Paris, France, 2-4 May 2005, 2005b.

Sgrigna, V., A. Buzzi, L. Conti, P. Picozza, C. Stagni, and D. Zilpimiani, Seismo-induced Effects in the Near-Earth Space: Combined Ground and Space Investigations as a contribution to Earthquake Prediction, Tectonophysics, 431, 153-171, 2006.

Sorokin, V. M., V. M. Chmyrev, and A. K. Yaschenko, Electrodynamic model of the lower atmosphere and the ionosphere coupling, J. Atm. Sol. Terr. Phys., 63, 1681-1691, 2001.

Stavrakas, I., C. Anastasiadis, D. Triantis, and F. Vallianatos, Piezostimulated currents in marble samples: Precursory and concurrent with failure signals, Natural Hazards Earth Systems Sci., 3, 243-247, 2003.

Surkov, V., ULF Electromagnetic Perturbations Resulting from the Fracture and Dilatancy in the Earthquake Preparation Zone, in Atmospheric and Ionospheric Electromagnetic Phenomena Associated with Earthquakes, edited by M. Hayakawa, pp. 371-382, TERRAPUB, Tokyo, 1999.

Teisseyre, R., Generation of electric field in an earthquake preparation zone, Ann. Geofis., 40, 297-304, 1997.

Thatcher, W. and N. Fujita, Deformation of the Mikata Rhombus: Strain Buildup Following the 1923 Kanto Earthquake, Central Honshu, Japan, J. Geophys. Res., 89, 2102-2106, 1984.

Tzanis, A. and F. Vallianatos, Distributed power-law seismicity changes and crustal deformation in the EW Hellenic Arc, Nat. Hazards Earth Systems Sci., 3, 2003.

Uyeda, S., K. Sulaiman Al-Damegh, E. Dologlou, and T. Nagao, Some relationship between VAN seismic electric signals (SES) and earthquake parameters, Tectonophysics, 304, 41-55, 1999.

Vallianatos, F. and A. Tzanis, A model for the generation of precursory electric and magnetic fields associated with the deformation rate of the earthquake focus, in Atmospheric and Ionospheric Electromagnetic Phenomena Associated with Earthquakes, edited by M. Hayakawa, pp. 287-305, TERRAPUB, Tokyo, 1999.

Vallianatos, F., D. Triantis, A. Tzanis, C. Anastasiadis, and I. Stavrakas, Electric earthquake precursors: from laboratory results to field observations, Phys. Chem. Earth, 29, 339-351, 2004.

Varotsos, P., K. Alexopoulos, M. Lazaridou, and T. Nagao, Earthquake predictions issued in Greece by seismic electric signals since February 6, 1990, Tectonophysics, 224, 269-288, 1993.

Varotsos, P., N. Sarlis, M. Lazaridou, and P. Kapiris, Transmission of stress induced electric signals in dielectric media, J. Appl. Phys., 83, 60-70, 1997.

Voronov, S. A., A. M. Galper, S. V. Koldashov, L. V. Maslennikov, V. V. Mikhailov, N. V. Nikitina, and A. V. Popov, Increases in High Energy Charged Particle Fluxes near the South Atlantic Magnetic Anomaly and the Seismicity of the Earth, Cosmic Res., 28, 789-791, 1990.

Warwick, J. W., C. Stoker, and T. R. Meyer, Radio emission associated with rock fracture: possible application to the great Chilean earthquake of May 22, 1960, J. Geophys. Res., 87, 2851-2859, 1982.

Zaslavski, Y., M. Parrot, and E. Blanc, Analysis of TEC measurements above active seismic reagions, Phys. Earth Planet. Inter., 105, 219-228, 1998.

V. Sgrigna (e-mail: sgrigna@fis.uniroma3.it), A. Buzzi, L. Conti, P. Picozza, C. Stagni, and D. Zilpimiani 